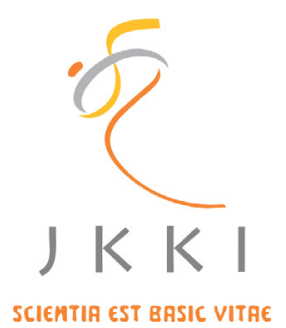

Jurnal Kedokteran dan Kesehatan Indonesia

Indonesian Journal of Medicine and Health

Journal homepage : https://journal.uii.ac.id/JKKI/index

\title{
Adopting mass thalassemia prevention program in Indonesia: A proposal
}

\author{
Lantip Rujito*1, Joko Mulyanto ${ }^{2}$ \\ ${ }^{1}$ Department of Molecular Biology, Faculty of Medicine, Universitas Jenderal Soedirman, Purwokerto \\ ${ }^{2}$ Department of Public Health and Community Medicine, Faculty of Medicine, Universitas Jenderal Soedirman, \\ Purwokerto
}

\begin{tabular}{|c|c|}
\hline \multirow{2}{*}{\multicolumn{2}{|c|}{$\begin{array}{l}\text { GUEST EDITORIAL } \\
\text { halassemia is a catastrophic disease with a genetic background that }\end{array}$}} \\
\hline & \\
\hline $\begin{array}{l}\text { *Corresponding author: } \\
\text { l.rujito@unsoed.ac.id }\end{array}$ & $\begin{array}{l}\text { has the most extensive clinical, psychological, and financial burden } \\
\text { in Indonesia. With a current total population of } 250 \text { million and } \\
\text { based on the thalassemia carrier prevalence of } 3-10 \% \text {, it was estimated }\end{array}$ \\
\hline DOI : 10.20885/JKKI.Vol10.Iss1.art1 & $\begin{array}{l}\text { using Hardy Weinberg's law for diseases with recessive inheritance, } \\
\text { around } 2500-3500 \text { babies per year are born with thalassemia major }\end{array}$ \\
\hline $\begin{array}{l}\text { Copyright @2019 Authors. } \\
\text { This is an open access article } \\
\text { distributed under the terms } \\
\text { of the Creative Commons At- } \\
\text { tribution-NonCommercial } 4.0 \\
\text { International Licence (http:// } \\
\text { creativecommons.org/licences/ } \\
\text { by-nc/4.0/). }\end{array}$ & $\begin{array}{l}\text { Currently, about } 9,000 \text { thalassemia patients are undergoing treatment } \\
\text { at thalassemia centres throughout Indonesia. However, this figure is } \\
\text { likely underestimated for several reasons such as the possibility of } \\
\text { underdiagnosed cases due to lack of access to healthcare facilities. }{ }^{1,2} \\
\text { Because of the characteristic of thalassemia as a financially catastrophic } \\
\text { disease, thalassemia treatment has been included in the benefits package } \\
\text { of government health insurance program for the poor (JAMKSESMAS) } \\
\text { since } 2010 \text { and the national health insurance (NHI) program since } 2014 \text {. } \\
\text { There is a growing concern about the increase of financial burden in } \\
\text { thalassemia treatment to the Indonesian healthcare system. Currently, } \\
\text { thalassemia is one of the five clinical conditions with the most substantial } \\
\text { financial claim in the NHI program, a significant increase from previous } \\
\text { years. The financial burden of thalassemia treatment has the potential } \\
\text { to grow exponentially in the following years considering the absence of } \\
\text { nation-wide thalassemia prevention program, an increase in the number } \\
\text { of patients per year, and treatment onset in the early year of life. }\end{array}$ \\
\hline
\end{tabular}

Prevention is the most effective method to manage the increased of thalassemia problems and has been exemplified by other endemic countries such as Cyprus, Italy, Iran, Israel, Thailand, and Malaysia. Cyprus as the pioneer in the prevention of thalassemia started the program 1980, resulted in the zero percentage of thalassemia major birth rates currently. ${ }^{3}$ Iran, a conservative Islamic state, issued fatwas for prenatal and medical abortion as part of the thalassemia prevention programs. ${ }^{3}$ Thailand with a carrier prevalence rate of up to $40 \%$ has launched the prevention programs since the 2000 s. $^{4}$

Indonesia, a lower-middle income country with a large population, diverse cultural background, and vast geographical areas face a major challenge to provide a nation-wide thalassemia prevention program. To address the problems of cultural diversity and inadequacy of healthcare resources, the thalassemia prevention program in Indonesia should consider the aspect of mass education, human resources and infrastructure development particularly for screening, as well as elements of the distribution of these resources.

Concerning mass education, a thalassemia prevention program in Indonesia may take several approaches. First, the inclusion of thalassemia content to the curriculum of primary and secondary 
school in Indonesia. The primary goal is to improve the understanding of students in thalassemia and their related problems. This goal can be gradually achieved by including the thalassemia content in curriculum across different level of education. At the primary level, the main emphasis should be on the familiarisation of thalassemia term to students as well as other common diseases such as diarrhoea, influenza, etc. At the lower secondary level, the knowledge of thalassemia for the student can be further improved by discussing the broader concept of thalassemias such as aetiology, inheritance patterns, and prevention programs. At the upper secondary level, the curriculum can be designed in such a way that the content of thalassemia is well-conveyed in specific courses such as general biology or reproductive biology. The particular material should discuss more advanced content such as recessive Mendel inheritance pattern, and the clinical conditions due to thalassemia. This can be expanded to other thalassemia-related contents such as severe clinical conditions due to complications, psychological burden, and financial burden. The concept of future thalassemia free, for instance by marital planning, may also be discussed at this level.

Second, the inclusion of thalassemia content into extracurricular activities. We reported peer cadre through scouting organisation, and junior Red Cross voluntaries increased knowledge and improve attitudes of the students towards thalassemia. Increased knowledge and awareness can also be triggered through thalassemia month activities in schools, quizzes, and various kinds of thalassemia-themed competitions. Third, it is also crucial to create more culturally-sensitive methods to deliver thalassemia content for instance by adopting the local language. This will increase the effectiveness of thalassemia content, particularly for the specific local population. In essence, the revision of the education curriculum become a strategic step in a successful mass education program in student population.

In line with the improvement of the curriculum in schools, mass education activities for the wider community must be encouraged. Mass media has an essential role in mass education activities for the wider community. A conscious campaign of thalassemia through the mass media can be carried out by thalassemia observers, educators, and stakeholders in the health sector. Other mass campaign strategies include the appointment of thalassemia ambassadors using influential public figures. The thalassemia ambassadors have the primary duty to convey the importance of thalassemia pre-marital screening to achieve thalassemia-free generations in the future.

The serial mass education activities are essential to prepare and enhance the public's readiness to the next step of thalassemia prevention program which is screening thalassemia carriers for targeted people. ${ }^{5}$ Carrier screening is the first fundamental step to thalassemia prevention and will be challenging for Indonesia because hundreds of different ethnic groups will undergo the test. Diverse culture creates a challenging environment in the implementation of new technologies or health interventions such as carrier screening program. This underlines the importance of structured and massive mass education intervention adjusted to the local language and culture which is aimed to increase the level of community acceptance for screening programs.

The implementation of the screening program can be divided into several levels of urgency based on the target population. The first target population is the extended family of thalassemia patients. Screening to this target population is considered as the most necessary and essential screening. A study showed approximately $50 \%$ of the extended family from thalassemia patient carried the mutant for the thalassemia gene. ${ }^{6}$ Screening for the extended family of thalassemia patient ensures their carrier status which will be an important basis for counselling program regarding their reproductive planning.

The second target population for mass screening is pregnant women who undergo antenatal care (ANC). Routine blood tests which are conducted in ANC can be followed up to assess the tendency of the mother to carry the thalassemia gene. If the mother is a positive carrier, a follow-up screening to determine the carrier status of the husband must be conducted. This type of screening is relatively feasible and affordable because routine blood tests are commonly performed in the ANC. However, results from screening using routine blood test from ANC should be interpreted cautiously. A study showed this screening succeeded to identify $7.7 \%$ of 1,320 pregnant women as a carrier of beta-thalassemia. Following-up screening to the husbands successfully identified several individuals who were also a carrier of the thalassemia. ${ }^{7}$

The third target population for screening program are couples who are planning to have children. This type of screening requires awareness from doctors to deliver proper counselling to the couples. 
However, the primary challenge to implement this type of screening is the unequal distribution of medical personnel in Indonesia particularly in peripheral regions and remote areas as well as in East Indonesia. Alternatively, midwives who more equally distributed in Indonesia and available at the village level can fulfil this function. The counselling process should be emphasised to provide options for couples who are planning to have children, such as screening preconceptions (PGD), or prenatal screening such as amniocentesis. However, a significant barrier to conducting prenatal testing is the limited availability of screening centres which mostly are located in big cities.

The fourth potential target population is students at school age or university students. Although most of them are not married yet and are not planning to have children shortly, they are categorised in the reproductive age, and some of them are sexually active. Screening for thalassemia for this target population provides information which will be beneficial to develop their future reproductive plan. The younger generation will be more consciously consider essential health condition such as thalassemia when they look for a life partner and planning having children. ${ }^{8}$ This approach can be more culturally and contextually refined by combining with another approach such as the inclusion of traditional (local) values. For instance, many Javanese people still firmly hold the values of bibit, bobot, and bebet when they look for their life partner. The inclusion of essential health conditions such as thalassemia into these values will likely lead to better adoption of the screening program to the community. Also of that, the involvement of indigenous stakeholders and religious leader will play an important role to disseminate information on thalassemia which culturally and contextually acceptable.

To systematically implement a national screening program for thalassemia requires a clear national health policy as a guideline. A well-defined national health policy will provide the legal basis to devote necessary resources which are needed for the program. This includes developing human resources and healthcare infrastructure, dissemination of screening tools, and regulate the role and responsibility between central and local government. ${ }^{9}$ Ministry of health should be responsible for providing adequate number of health personnel, developing the capabilities, and distribute equally through the country. A specific capacity building program should involve the skill of hematology analysis interpretation, and the competence to provide proper counselling to the target population. There is also a need to develop a service network by using academic centres to cover more advanced test such as genetic analysis to complete the detection process. Last but not least, the thalassemia screening program must be equally accessible for all population groups in Indonesia regardless of socioeconomic, cultural, and geographical background. A possible option to provide equitable access to the thalassemia screening program is by including the program as part of the $\mathrm{NHI}$ benefit. Reducing the thalassemia disease burden by implementing nation-wide prevention program has been proved useful in many endemic countries. It is our turn to take the first step toward thalassemia-free generation in Indonesia.

\section{REFERENCES}

1. Kementerian Kesehatan Republik Indonesia. Pencegahan thalassemia (Hasil kajian Health Technology Assesment tahun 2009). Dirjen Bina Pelayanan Medik Kementerian Kesehatan Republik Indonesia, editor. Jakarta; 2010.

2. Rujito L. Genetic counseling in Indonesia as a mandatory service. Jurnal Kedokteran dan Kesehatan Indonesia. 2018; 30;9(1):1-2.

3. Kolnagou A, Kontoghiorghes GJ. Advances in the prevention and treatment are changing thalassemia from a fatal to a chronic disease. Experience from a Cyprus model and its use as a paradigm for future applications. Hemoglobin. 2009; 33(5):287-95.

4. Viprakasit V, Limwongse C, Sukpanichnant S, Ruangvutilert P, Kanjanakorn C, Glomglao W, et al. Problems in determining thalassemia carrier status in a program for prevention and control of severe thalassemia syndromes: A lesson from Thailand Vol. 51. Clinical Chemistry and Laboratory Medicine. 2013. p. 1605.

5. Wong LP, George E, Tan J-AMA. A holistic approach to education programs in thalassemia for a multi-ethnic population: Consideration of perspectives, attitudes, and perceived needs. Journal of Community Genetics.2011;2(2):71-9.

6. Ahmed S, Saleem M, Modell B, Petrou M. Screening extended families for genetic hemoglobin 
disorders in Pakistan. The New England Journal of Medicine. 2002;347(15):1162-8.

7. Baxi A, Manila K, Kadhi P, Heena B. Carrier screening for $\beta$ thalassemia in pregnant Indian women: Experience at a single center in Madhya Pradesh. Indian Journal of Hematology and Blood Transfusion. 2013;29(2):71-4.

8. Cousens NE, Gaff CL, Metcalfe SA, Delatycki MB. Carrier screening for beta-thalassaemia: A review of international practice. European Journal of Human Genetics. 2010;18(10):1077-83.

9. Cao A, Kan YW. The prevention of thalassemia. Cold Spring Harbor Perspectives in Medicine. 2013;3(2):1-16. 